\title{
Genetic Recombination in Caulobacter
}

\author{
By J. D. JOLLICK AND ELLA M. SCHERVISH \\ Department of Microbiology, Wayne State University \\ School of Medicine, Detroit, Michigan, U.S.A.
}

(Received I5 May 1972; revised 10 July 1972)

\begin{abstract}
SUMMARY
Auxotrophic, phage-resistant and streptomycin-resistant mutants of Caulobacter were used to demonstrate genetic recombination in this genus. Forty of a possible I 70 mating pairs gave recombinant frequencies of from 100 to 1000 times greater than reversion frequencies for the markers used. Stability of the recombinants was demonstrated by successive cloning on both complete and minimal medium. Cell contact is apparently required for recombination since both cell types of a mating pair must be present for prototroph formation.
\end{abstract}

\section{INTRODUCTION}

Caulobacter is a stalked pseudomonad found in aquatic, marine and soil environments. This genus has been characterized by Poindexter (I964), and Schmidt \& Stainer (I965) have reported both DNA and RNA containing bacteriophage for Caulobacter. Because of its diphasic life cycle this organism has been suggested as a model for the study of cell differentiation. Caulobacter exhibits two distinct morphological types, a non-motile stalked cell and a motile cell with no stalk. The motile cell is the immature antecedent to the stalked form. Stalk formation precedes cell division from which two daughter cells, one stalked, the other motile, arise. The stalked cell may divide indefinitely, while the motile cell must first form a stalk before division. The desirability of developing a system of genetic analysis is apparent, if Caulobacter is to be used as a model for differentiation studies. Shapiro, Agabian-Keshishian \& Bendis (1971) have introduced evidence for genetic recombination in Caulobacter. This report substantiates her finding and presents additional information concerning genetic recombination in Caulobacter.

\section{METHODS}

Organisms. Caulobacter crescentus ATCC I9089 was chosen as the wild parent prototroph for derivation of auxotrophic mutants. The strain designation $\mathrm{CBI} 5$, used by Poindexter (I964), is retained in this paper.

RNA bacteriophage ATCC ${ }_{19089} B_{1}\left(\phi B_{1}\right)$, was used to select phage-resistant mutants of the auxotrophs.

Growth conditions. Cultures were incubated at $30{ }^{\circ} \mathrm{C}$ in all experiments. The complete medium was the Peptone Yeast extract (PYE) medium of Poindexter (1964). The chemically defined (minimal) medium consisted of : glucose, $0.2 \% ;\left(\mathrm{NH}_{4}\right)_{2} \mathrm{SO}_{4}, 0 . \mathrm{I} \% ; \mathrm{K}_{2} \mathrm{HPO}_{4}, 0.05 \%$; $\mathrm{KH}_{2} \mathrm{PO}_{4}, 0.05 \% ; \mathrm{MgSO}_{4} .7 \mathrm{H}_{2} \mathrm{O}, 0.0 \mathrm{I} \%$; agar, $\mathrm{I} \cdot 5 \%$. Bacteriophage were propagated on the complete medium by the agar layer method of Adams (1959).

Isolation of auxotrophs. A $15 \mathrm{ml}$ PYE broth culture of the parent strain containing 
$2 \cdot 0 \times 10^{8}$ colony-forming units (c.f.u.) $/ \mathrm{ml}$ was centrifuged and resuspended in $10 \mathrm{ml}$ of a fresh, filter-sterilized saline solution of $N$-methyl- $N$-nitro- $N$-nitrosoguanidine (NTG), $0.02 \%$. The suspension was incubated at $30{ }^{\circ} \mathrm{C}$ for $20 \mathrm{~min}$. After incubation the cells were sedimented by centrifugation and resuspended in fresh PYE broth. Serial tenfold dilutions of the treated cells were plated on PYE agar. Colonies of survivors of NTG treatment were then picked to complete (PYE) and minimal agar plates. Auxotrophs were identified as those isolates which grew on complete but not on minimal medium. The growth requirements of the auxotrophs were established by streaking the auxotroph on the minimal medium and then applying small filter paper discs saturated with solutions containing six amino acids. The procedure was then repeated using solutions of single amino acids to establish the exact growth requirement.

Isolation of streptomycin-and phage-resistant auxotrophs. Phage-resistant mutants of the auxotrophs were selected by an enrichment technique. Phage-infected broth cultures (MOI I-IO) were serially passed through five $48 \mathrm{~h}$ subcultures. A small sample from the fifth passage was streaked on complete agar, the colonies were picked and tested for phage resistance and retention of auxotrophy. Auxotrophs were tested for phage resistance by dropping serial tenfold dilutions of a high titre phage suspension on a PYE overlay seeded with the strain in question. Sensitive strains showed plaque formation in the spot areas. Resistant strains were unaffected by the phage at all dilutions tested.

Streptomycin-resistant mutants were selected by spreading a $24 \mathrm{~h}$ PYE broth culture containing $2.5 \times 10^{10} \mathrm{c}$.f.u. $/ \mathrm{ml}$ on a streptomycin gradient plate. The antibiotic concentration was from o to $200 \mu \mathrm{g} / \mathrm{ml}$. Streptomycin resistance was tested using PYE agar plates with streptomycin added to a final concentration of $100 \mu \mathrm{g} / \mathrm{ml}$.

Mating experiments. The matings were performed by mixing $\mathrm{I} \cdot \mathrm{O} \mathrm{ml}$ of an $\mathrm{I} 8$ to $24 \mathrm{~h}$ PYE broth culture of each partner. The titre of the individual strains was standardized to 1.5 to $3.0 \times 10^{8}$ c.f.u. $/ \mathrm{ml}$ before mixing. The mixture was incubated at $30^{\circ} \mathrm{C}$ for $2.0 \mathrm{~h}$ then $0 . \mathrm{I} \mathrm{ml}$ of each mixture was spread on minimal agar, incubated and the colonies scored. For controls, each individual strain was also plated in like numbers on minimal agar to check for reversion to prototrophy.

\section{RESULTS AND DISCUSSION}

Nineteen independent amino acid-requiring auxotrophs with various combinations of phage and streptomycin resistance were obtained from the wild parent (Table I). Eight of them were made phage-resistant, and three stable streptomycin-resistant mutants were also acquired.

All mating combinations possible with the nineteen strains were tried. The results of several typical mating experiments are presented in Table 2. Although only thirteen crosses are shown in Table 2, forty of the 170 possible mating pairs consistently produced prototrophs at a frequency of from 100 to 1000 times greater than observed by reversion of the auxotrophs. The recombination frequency for prototrophy in our best system was one recombinant $/ \mathrm{IO}^{5}$ pairs plated. Shapiro et al. (197I) reported a frequency of recombination of $\mathrm{I} \cdot 5$ to $\mathrm{I} \cdot 7 \times 10^{-6}$ with their str-s bio ${ }^{+}$and str-r bio $^{-}$strains. These frequencies are lower than the ones we report here. The differences may reflect the different strains or mating technique employed. Shapiro reports a spontaneous reversion rate for her str-r to $s t r-s$ of $2 \times 1 \mathrm{IO}^{-8}$ which is very close to that of our $\mathrm{CB} I 5$ auxotrophs where the highest spontaneous reversion frequency observed was $2.5 \times 10^{-8}$.

The stability of the presumed recombinants was tested several ways. Sixty individual recombinant colonies from each positive cross were picked and streaked on both minimal 
Table 1. Genotypes of mutants derived from Caulobacter crescentus ATCC 19089

Strain designation
CBI5 (ATCC I 9089)
CBI5 AI
A2
A3
A4
A5
A6
A7
A8
A9
A10
A1 I
AI2
A13
A2 I
A23
A25
A28
A39
A40

\begin{tabular}{|c|c|}
\hline \multicolumn{2}{|c|}{ Genotype } \\
\hline Prototroph & $\phi \mathrm{B}_{1}-s$ str-s \\
\hline asp-I & $\phi \mathrm{B}_{1}-r$ st $r-r$ \\
\hline his-I & $\phi \mathrm{B}_{1}-r s t r-r$ \\
\hline$a s p-2$ & $\phi \mathrm{B}_{1}-s$ str-s \\
\hline his-2 & $\phi \mathrm{B}_{1}-r$ str-s \\
\hline his-3 & $\phi \mathrm{B}_{1}-s$ str-s \\
\hline his-4 & $\phi \mathrm{B}_{1}-s$ str-s \\
\hline met-I & $\phi \mathrm{B}_{1}-r$ str-r \\
\hline met-2 & $\phi \mathrm{B}_{1}-r$ str-r \\
\hline his-5 & $\phi \mathrm{B}_{1}-s$ str-s \\
\hline$g l y-I$ & $\phi \mathrm{B}_{1}-r$ str-s \\
\hline $\operatorname{tr} y-1$ & $\phi \mathrm{B}_{1}-r$ str-s \\
\hline met-3 & $\phi \mathrm{B}_{1}-r$ str-s \\
\hline his -6 & $\phi \mathrm{B}_{1}-s$ str-s \\
\hline$m e t-4$ & $\phi \mathrm{B}_{\mathrm{I}}-s$ str-s \\
\hline met -5 & $\phi \mathrm{B}_{1}-s$ str-s \\
\hline ser-I & $\phi \mathrm{B}_{1}-s$ str-s \\
\hline $\operatorname{try} y-2$ & $\phi \mathrm{B}_{1}-s$ str-s \\
\hline $\operatorname{try} y-3$ & $\phi \mathrm{B}_{1}-s$ str-s \\
\hline met-6 & $\phi \mathrm{B}_{1}-s$ str-s \\
\hline
\end{tabular}

Table 2. Recombinants formed from auxotrophic mating pairs

\begin{tabular}{|c|c|c|c|c|}
\hline Mating pair & Controls* & $\begin{array}{l}\text { Recombinations } \dagger \\
\text { (prototrophs) }\end{array}$ & $\begin{array}{l}\text { Frequency of } \\
\text { prototroph } \\
\text { formation by } \\
\text { reversion (per } 10^{5} \\
\text { cells plated) }\end{array}$ & $\begin{array}{l}\text { Frequency of } \\
\text { prototroph } \\
\text { formation by } \\
\text { recombination } \\
\text { (per } 10^{5} \text { mating } \\
\text { pairs plated) }\end{array}$ \\
\hline $\mathrm{AI} \times \mathrm{A} 7$ & $0, I$ & $1000 \div$ & 0.0005 & $\mathrm{I} \cdot 00$ \\
\hline $\mathrm{AI} \times \mathrm{AIO}$ & 0,2 & 296 & 0.001 & 0.30 \\
\hline $\mathrm{A} 4 \times \mathrm{A} 7$ & $I, I$ & 1000 & 0.001 & I.0O \\
\hline $\mathrm{A} 4 \times \mathrm{AI}_{1} 2$ & 1,1 & 1000 & 0.001 & $I \cdot 00$ \\
\hline A $5 \times$ A 7 & $0, \mathbf{I}$ & 103 & 0.0005 & 0.10 \\
\hline A5 $\times$ A10 & 0,2 & 45 & 0.001 & 0.05 \\
\hline $\mathrm{A} 5 \times \mathrm{AI} 2$ & 0,1 & 65 & 0.0005 & 0.05 \\
\hline$A 3 \times A 2 I$ & 3,0 & 1000 & 0.0015 & $1 \cdot 00$ \\
\hline A $3 \times$ A23 & 3,0 & 1000 & 0.0015 & $1 \cdot 00$ \\
\hline $\mathrm{A} 3 \times \mathbf{A} 25$ & 3,2 & $30 \mathrm{I}$ & 0.0025 & 0.30 \\
\hline $\mathrm{A} 3 \times \mathrm{A} 40$ & 3,1 & 1000 & 0.002 & $I \cdot 00$ \\
\hline A1 $3 \times$ A2 5 & 0,2 & 203 & 0.001 & 0.20 \\
\hline $\mathrm{A} 13 \times \mathrm{A} 4 \mathrm{O}$ & $0, \mathbf{I}$ & 40 & 0.0005 & 0.04 \\
\hline
\end{tabular}

* Average number of colonies appearing on minimal medium when the parent cultures are plated alone. + Average number of colonies appearing on minimal medium when the mating pair mixtures are plated. \$ Actual counts ranged from 800 to 1300 colonies in repeated experiments.

and complete media and then five randomly chosen colonies from each were picked and passed at least twice more on minimal. Recombinant colonies were also picked to complete broth, assayed for viable count on both complete and minimal agar then streaked on minimal for three passes. Only two of the crosses tested showed less than $90 \%$ of the colonies picked to be unstable prototrophs. A random check of the stability of the prototrophs formed from various matings is shown in Table 3.

Progeny of several of the crosses were examined for the two unselected markers: phage resistance and streptomycin resistance. Unfortunately some of the mating combinations 
Table 3. Stability of prototrophy in recombinants from auxotrophic mating pairs

\begin{tabular}{|c|c|c|c|}
\hline Mating pair & $\begin{array}{c}\text { Total no. of } \\
\text { presumed } \\
\text { recombinants tested }\end{array}$ & $\begin{array}{l}\text { No. of recombinant } \\
\text { colonies demonstrating } \\
\text { stable prototrophy }\end{array}$ & $\begin{array}{c}\text { Stable } \\
\text { recombinants }(\%)\end{array}$ \\
\hline $\mathrm{AI} \times \mathrm{A} 7$ & 60 & 60 & 100 \\
\hline $\mathrm{AI} \times \mathrm{AIO}$ & 60 & 60 & 100 \\
\hline $\mathrm{A} 4 \times \mathbf{A} 7$ & 60 & 58 & 97 \\
\hline $\mathrm{A} 4 \times \mathrm{AI} 2$ & 52 & 49 & 94 \\
\hline A5 $\times$ A 7 & 37 & 34 & 92 \\
\hline A5 $\times$ AIO & 45 & 43 & 95 \\
\hline A $5 \times$ AI 2 & 60 & 60 & 100 \\
\hline $\mathrm{A} 3 \times \mathrm{A} 2 \mathrm{I}$ & 60 & 35 & 54 \\
\hline $\mathrm{A} 3 \times \mathrm{A} 23$ & 60 & 59 & 99 \\
\hline $\mathrm{A} 3 \times \mathrm{A} 25$ & 60 & 57 & 95 \\
\hline A3 $\times$ A40 & 60 & 58 & 97 \\
\hline A1 $3 \times$ A25 & 60 & 57 & 95 \\
\hline $\mathrm{AI} 3 \times \mathrm{A} 4 \mathrm{O}$ & 40 & 40 & 100 \\
\hline
\end{tabular}

Table 4. Crosses between mating partners with triple marker differences

\begin{tabular}{|c|c|c|c|}
\hline Cross & $\begin{array}{l}\text { Genotypes of } \\
\text { mating partners }\end{array}$ & $\begin{array}{l}\text { Genotypes possible in } \\
\text { recombinants }\end{array}$ & $\begin{array}{c}\text { Recombinants } \\
\text { of each } \\
\text { genotype }(\%)\end{array}$ \\
\hline $\mathrm{A} 3 \times \mathrm{A} 7$ & $\begin{array}{c}\text { met }^{+} \text {asp-2 } \phi \mathrm{B}_{1}-s \text { str-s } \\
\times \\
\text { met-I asp }{ }^{+} \phi \mathrm{B}_{1}-r \text { str-r }\end{array}$ & $\begin{array}{l}m^{+} t^{+} a s p^{+} \phi \mathrm{B}_{1}-s \text { str-s } \\
m^{+} t^{+} a s p^{+} \phi \mathrm{B}_{1}-s \text { str-r } \\
m^{+} t^{+} a s p^{+} \phi \mathrm{B}_{1}-r \text { str-s } \\
m e t^{+} a s p^{+} \phi \mathrm{B}_{1}-r \text { str-r }\end{array}$ & $\begin{array}{r}96 \\
0 \\
4 \\
0\end{array}$ \\
\hline $\mathrm{A} 25 \times \mathrm{A} 7$ & $\begin{array}{c}\text { met }^{+} \text {ser-I } \phi \mathrm{B}_{1}-s \text { str-s } \\
\times \\
\text { met-I ser }{ }^{+} \phi \mathrm{B}_{1}-r \text { str-r }\end{array}$ & $\begin{array}{l}\text { met }^{+} \text {ser }^{+} \phi \mathrm{B}_{1}-s \text { str-s } \\
\text { met }^{+} \text {ser }^{+} \phi \mathrm{B}_{1}-r \text { str-r } \\
\text { met }^{+} \text {ser }^{+} \phi \mathrm{B}_{1}-r \text { str-s } \\
\text { met }^{+} \text {ser }^{+} \phi \mathrm{B}_{1}-r \text { str-r }\end{array}$ & $\begin{array}{r}90 \\
0 \\
10 \\
0\end{array}$ \\
\hline
\end{tabular}

that would have provided the most information did not produce prototrophs. However, several positive crosses occurred between partners with at least two different markers: one the auxotrophic marker and either phage or streptomycin resistance. In two of the positive crosses, auxotrophs A $7 \times \mathrm{A} 25$ and A3 $\times$ A 7 , the parents had three different markers: Table 4 illustrates the genotypes of the mating pairs and the expected and observed progeny from each cross.

Since we were selecting for prototrophy all recombinants would be $m e t^{+} a s p^{+}$in the first cross and $\mathrm{met}^{+} \mathrm{ser}^{+}$in the second. The other markers could theoretically be found in any of the combinations shown. However, none of the recombinants we tested were streptomycin resistant. We have insufficient data to speculate as to the reason for this observation. The mechanism of genetic transfer is presumed to be conjugation since preliminary tests indicate that both cell types must be present in the mating mixtures and supernatants of one member of a positive pair when mixed with viable cells of its partner do not produce prototrophs. This observation supports Shapiro's contention that cell contact is required for genetic exchange.

Many aspects of the genetics of Caulobacter remain to be explored. However, the stability of the prototrophs derived from the auxotrophic mating pairs, and the indication of reshuffling of the phage and antibiotic resistant markers seen in the examination for unselected characteristics, provide evidence for genetic recombination in Caulobacter. 
This investigation was supported in part by NIH General Research Support Grant RR-05384.

\section{REFERENCES}

Adams, M. H. (1959). Bacteriophages. New York: Interscience Publishers.

PoINDEXTER, J. S. (I964). Biological properties and classification of the Caulobacter group. Bacteriological Reviews 28, 23I-295.

Schmidt, J. M. \& Stanier, R. Y. (1965). Isolation and characterization of bacteriophages active against stalked bacteria. Journal of General Microbiology 39, 95-107.

Shapiro, L., Agabian-Keshishian, N. \& Bendis, I. ( I971). Bacterial differentiation. Science, New York r73, $884-892$. 